\title{
A VUELTAS CON CELESTINA-BRUJA Y EL CORDON DE MELIBEA ${ }^{1}$
}

\author{
Ángel Gómez Moreno y Teresa Jiménez Calvente.
}

\author{
A Teresa y Paco Márquez Villanueva.
}

Hoy queda fuera de toda duda que Fernando de Rojas, en su caracterización de Celestina, recurrió a una doble tradición: por una parte, encontró fundamentos para su personaje en aquellas obras literarias que, previamente, habian acogido a alcahuetas, lenas o terceras; por otra, al perfilar su retrato, el bachiller de La Puebla hubo de apelar por fuerza a su propia observación de una realidad que ofrecía pocos cambios a través de los tiempos: el mundo marginal de putas, rufianes y demás gente de mal vivir. Puestos a espigar materiales de uno y otro lado, la primera de esas tradiciones se revela insuficiente por si sola cuando hay que documentar los rasgos distintivos de Celestina en obras previas; a este respecto, en la literatura clásica como en la medieval, la acordadora de amores rara vez aparece revestida de las facultades de curandera, hechicera o, en el último de los grados posibles, bruja.

Cuando María Rosa Lida de Malkiel, en La originalidad artística de La Celestina, Buenos Aires, 1962, decidió perseguir las señas de identidad de la vieja en el teatro clásico, comprobó que su figura sólo aparecía perfilada con nitidez ( $\mathrm{y}$ ello con una función meramente ancilar, y nunca mejor dicho)

\footnotetext{
1 Hay que adjuntar una referencia reciente en que se atiende a la figura de la lena desde la otra vertiente de los estudios celestinescos: la semítica, oriental, hispano-árabe e hispano-hebrea; nos referimos al inteligente trabajo, como el resto de los suyos, de Francisco Márquez Villanueva, "Para el encuadre del tema celestinesco: el tratado de alcahuetería de Nafzawi", La Torre (NE), 7, 1993, págs. 147-169. Este trabajo es un magnífico complemento de su libro Orígenes y sociología del tema celestinesco, Barcelona, 1993. En nuestras páginas se revisa en parte la otra corriente crítica tradicional, latina y europea, conjugada con la propiamente hispánica. De ultimísima hora es el panorama sobre uno de los aspectos que nos interesan por parte de Patrizia Botta, "La magia en La Celestina", Dicenda. Cuadernos de Filología Hispánica, 12, 1994, páginas 37-67.
} 
tan sólo en dos de las comedias de Plauto: la Asinaria y la Cistellaria ${ }^{2}$. Ahora bien, ninguna de estas dos comedias plautianas concede a su lena atributos de hechicera ; con Celestina, tales terceras comparten únicamente un rasgo característico: su afición desmedida al vino, que, para Lida, puede ser un claro reflejo del teatro romano. Sin embargo, de acuerdo con nuestro parecer, que sospechamos es el de muchos estudiosos, la dependencia a ese respecto resulta del todo innecesaria. En otros momentos, la sabia investigadora argentina extendió su rastreo hasta textos muy alejados del universo de La Celestina aunque tal vez conocidos por Rojas, como las Elegiae de Propercio o los Amores de Ovidio, donde las lenas son al mismo tiempo magas ${ }^{3}$. De los textos del Medievo que cita, sólo la vieja de la comedia elegiaca Baucis et Trasso es dibujada con mañas de bruja (vv. 153 y siguientes) y como hábil remendadora de virgos (desde el v. 307 al final, donde se inserta una lista jocosa de ingredientes que son meros impossibilia: ojos de un ciego, pelo de la frente de un calvo, calor de un difunto o testículos de eunuco) ${ }^{4}$; no obstante, cabe rechazar cualquier relación directa entre $L a$ Celestina y esta obra, de la que solamente se conserva un único manuscrito ultramontano ${ }^{5}$. Conocedora como pocos de los textos clásicos, medievales y renacentistas, españoles y foráneos, Lida persiguió otros posibles contrastes de valor relativo: de hecho, muy poco tienen que ver con Celestina las alcahuetas que asoman en las Heroidas y las Metamorfosis ovidianas o en el Tristán, por aludir sólo a algunas obras conocidas por cualquier lector a finales del siglo $\mathrm{xv}^{6}$.

2 Al menos hubo un ejemplar de Plauto entre los fondos de los colegios de la Universidad de Salamanca (ms. 1807), según se revela en Lisardo Rubio, Catálogo de los manuscritos clásicos latinos existentes en España, Madrid, 1984, pág. 460; por otra parte, la presencia de un manuscrito del siglo xv que contiene una Comoedia carmine latino composita ad imitationem Amphitrionis M. A. Plawti (ms. 72) permite sospechar el éxito del clásico en esas aulas.

3 Amén de un puñado de manuscritos, había varias ediciones incunables de ambos clásicos en circulación por toda Europa; de su presencia en la Península no cabe duda, según se deduce del recién citado trabajo de Lisardo Rubio y del Catálogo General de Incunables en Bibliotecas Españolas, Madrid, 1990.

- Son recetas burlescas que, en distintas maneras, aparecen a lo largo de nuestra literatura áurea; como ejemplo, viene bien el ms. 570 de la Biblioteca de Palacio, que recoge una Recepta muy aprobada para enrrubiar el cauello, que, habiéndolo, quedará tan rubio como el oro del pretal del Papa Eusenio Octawo y jamás desdise la color: "Primeramente un pedazo del cuerno de la luna y un manojo o dos de los rraios del sol y un quarto del luzero de el alba y vnos pelicos de las siete cabrillas" (fol. 61r). Tampoco cabe trazar ningún nexo entre esta burla de mediados del siglo xvi y la comedia elegiaca a la que hacemos referencia.

- La tradición manuscrita no ha experimentado ningún cambio desde la vieja edición del equipo de Gustave Cohen, en el volumen II de La "Comédie" latine en France an $X I I^{\bullet}$ siecle, París, 1931, hasta el volumen III de la edición a cargo de Ferruccio Bertini y su grupo, Commedie latine del XII e XIII secolo, Génova, 1980.

- Aunque la fortuna textual del Tristón sea mínima antes de 1501 y siempre quede 
Asi pues, Celestina es, en cierta medida, el resultado de una larga y aquilatada tradición literaria que presenta grados de relación muy diversos; sin embargo, la vieja artera es también el reflejo artístico de una figura propia de la sociedad de aquel momento que, paulatinamente, se iba procurando un espacio en el ámbito literario. Porque ofrece un magnífico retrato de su épo$\mathrm{ca}$, conviene volver la vista hacia ese delicioso manual de confesores que es el Libro de las confesiones de Martín Pérez (escrito 1312 a quo y 1317 ad quem $)^{7}$. Entre las diferentes ocupaciones y los diversos estratos sociales que merecen la atención de ese autor, su manual incorpora un modelo de confesión especial para buhones, con establecimiento o ambulantes; según el capitulo CLXX ("De los bohones, en qué cosas pecan"), estos profesionales incurren en grave pecado al vender afeites, hierbas e ingredientes para hacer maleficios (citamos a través del ms. 713 de la Fundación LázaroGaldiano, estragado por las tintas corrosivas y por el laminado con que se restauró, fols. $264 \mathrm{v}-265 \mathrm{r})$ :

[...] aluayalde o arrebol o otras colores a las mugeres, que saben que las quieren para se afeytar e presçiarse de fermosura vana [...] algunas simientes o rrayzes o algunas cosas mortales a sabiendas a persona que sopiesen por çierto o persona sospechosa que faría mal con ellas. Sy vendieron o traxieron en su tienda a sabiendas algunas cosas para fazer malefiçios o escantamientos o algunos males o todas estas cosas, diles que ellos han de dar cuenta a Dios de todos los daños que por ende contesçieron.

Sobre ese mismo grupo había dejado caer parecidas advertencias en el capítulo CXLII ("De los ofiçios que son más con daño que con pro e de las demasías de los vanos menesteres"). Este tratado, que ilumina distintos pasajes del Libro de Buen Amor (ya sea en su totalidad, por lo que atañe a los clérigos concubinarios, o en episodios aislados como el de Cruz, la pana-

lejos de la enorme difusión de los textos ovidianos, son numerosas las muestras indirectas del éxito de la leyenda desde el siglo xrv, según se desprende de una sencilla consulta al tradicional capítulo de María Rosa Lida de Malkiel, "La literatura artúrica en Espafia y Portugal", en sus Estudios de literatura española y comparada, Buenos Aires, 1966, págs. 134-148. Las terceras de Plauto y las olvidadas de Tibulo y Apuleyo forman la base del estudio de Tomás González Rolán, "Rasgos de la alcahuetería en la literatura latina", en Manuel Criado de Val, ed, "La Celestina" y su contorno social: Actas del Primer Congreso Internacional sobre La Celestina, Barcelona, 1977, págs. 275289, quien alaba, con razón, los tempranos esfuerzos de Antonio Bonilla y San Martín, "Antecedentes de tipo celestinesco en la literatura latina", Revue Hispanique, 15, 1906, págs. 372-386, sin olvidar los de Marcelino Menéndez y Pelayo y, lunares aparte, los de Francisco Castro Guisasola. Del trabajo de González Rolán son especialmente interesantes los documentos relativos a los diversos tipos de lena.

7 Para este autor y su obra, en espera de la prometida edición de Antonio García y García y su equipo, cabe remitir a las notas bibliográficas y fragmentos reunidos por Ángel Gómez Moreno en El teatro medieval castellano en su marco románico, Madrid, 1991. 
dera), engarza en ese punto, velis nolis, con toda una larga tradición literaria en la que la mujer malvada (alcahueta o bruja) encuentra camino franco gracias a la profesión con que se encubre ${ }^{8}$. A este respecto, la vida diaria, el folklore (como enseguida veremos) y la literatura coinciden a la hora de dibujar con contornos precisos la figura de la trotaconventos de don Melón, caracterizada de un plumazo en el verso 699a de Juan Ruiz: "Era vieja buhona, destas que venden joyas"; idéntico oficio tiene Urraca en la historia inmediatamente posterior, como leemos en el verso 937a: "Fizose corredera, de las que venden joyas", o bien en la copla $938^{\circ}$ :

E otrosí vos dixe que estas tales buhonas andan de casa en casa vendiendo muchas donas; non se reguardan d'ellas, están con las personas: fazen con el su viento andar las atahonas.

Por lo que respecta a la historia de don Melón (y la posterior del Arcipreste, que es puro trasunto de ésta), no tiene sentido la búsqueda de una correspondencia exacta en el Pamphilus, pues la empresa que acomete aqui la anus en ningún momento precisa de tapadera; a este respecto, conviene recordar que el forzamiento de Galatea por Pánfilo tiene lugar en la casa de aquélla y no en la de la joven ${ }^{10}$.

Más avisada ha andado la crítica a la hora de seguir los pasos de la vieja en el Laberinto de Fortuna o El Corbacho, pues hay trazas de tales dueñas dentro del episodio de la maga de Valladolid o en la larga retahíla de pecadoras del Arcipreste de Talavera ". A finales de esa centuria, su presencia se descubre, ahora por fin en clave literaria y jocosa (la más grata también para la mayoría de los continuadores, imitadores y deudores de Rojas), entre

- El último estudio aparecido, de Antonio García y García, Francisco Cantelar y Bernardo Alonso, "El Libro de las confesiones de Martín Pérez", Revista Española de Derecho Canónico, 49, 1992, págs. 77-129, recoge el prólogo, las tablas y unos cuantos capítulos de la obra; ahí se incluye, precisamente, el relativo a la panadera. Este trabajo actualiza en buena parte el de García y García en sus Estudios sobre la canonística portuguesa medieval, Madrid, 1976, págs. 201-217.

- Para las innumerables asociaciones con dicho oficio, véase el capítulo dedicado a "The Go-Between" por Gail Phillips, The Imagery of the 'Libro de Buen Amor', Madison, 1983, págs. 135-142.

10 En el Ars amandi ovidiana, la figura principal es la criada de la joven, que ha de hacer de intercesora (v. 351 y sigs.). La medianera del De vetula, dibujada como linguipotens y mendacissima, tampoco precisa de mercaderias para colarse en las casas, como cabe deducir tras la lectura de Paul Klopsch, ed., Pseudo-Ovidius 'De Vetula'. Untersuchungen und Text, Leiden y Colonia, 1967.

11 El estudio de los nexos entre esta obra y La Celestina apura posibilidades en Michael E. Gerli, “Celestina, Act I, reconsidered: Cota, Mena ... or Alfonso Martínez de Toledo?", Kentucky Romance Qwarterly, 23, 1976, págs. 29-45, donde se recogen otras propuestas previas. 
las comadres de la poesía de Rodrigo de Reinosa. Por otra parte, la figura de la medianera se intuye en algunas de las herramientas empleadas por Amor en el Diálogo de amor y un viejo de Rodrigo de Cota, que son capaces de hacer más bellas a las damas con afeites diversos; en palabras del viejo, Amor no duda en apelar a algunas de las artes prohibidas ("las quarenta [que] son vedadas e supersticiosas ho que enderesçan a provechos particulares e non ha bien común", según la glosa a su traducción de la Eneida de don Enrique de Villena, que cito por el ms. 17975 BNM, fol. $46 \mathrm{v})^{12}$ :

Tú vas a los adeuinos. tú buscas los hechizeros, tú consientes los agüeros y prenósticos mezquinos.

De entre todas las scibilidades citadas por Villena, la que aqui nos interesa es la amatoria, cuya relación con La Celestina ha sido considerada por Pedro Cátedra en un sólido trabajo ${ }^{13}$. La calle ofreció materia de sobra a todos esos autores, como se la brindó también a aquellos que, animados por la lectura de La Celestina, buscaron temas en las capas más bajas de la sociedad. En definitiva, cabe concluir que la literatura que atiende a los marginados se puede ver estimulada por las obras previas en que éstos aparecen; sin embargo, la impronta de la realidad es mucho más poderosa que la libraria en tales ocasiones. Esta afirmación vale para la novela picaresca como para Cervantes o Quevedo, en el caso de la narrativa naturalista como en del teatro de Valle-Inclán o, por referirnos a un medio distinto, en las películas de Buñuel. Sin lugar a duda, la Salamanca universitaria que conoció Rojas ( $\mathrm{y}$ aún la de hoy, con su barrio chino enclavado bajo los propios colegios), hubo de ser una fuente de inspiración mucho más poderosa a este respecto que cualquiera de las lecturas que hemos citado anteriormente.

La morbosa atracción por ese inframundo lo es por una serie de elementos que se repite de forma inmutable a lo largo de los siglos (en el nuestro, a ellos, claro está, hay que unir un nuevo ingrediente no menos morboso: las drogas y su entorno). Sin necesidad de salir de ese ámbito, descubrimos todas las señas de identidad del universo celestinesco y los rasgos característicos de la vieja ; sin embargo, la literatura (española como europea o universal) ha de venir una y otra vez en nuestro socorro en caso de apuro. Así,

$1 s$ A este esquema ha atendido no hace mucho Carla de Nigris, "La classificazione delle arti magiche di Enrique de Villena", Quaderni Ibero-Americani, 53-54, 1979-1980, págs. 289-298, aunque resulte dudoso su propuesto origen en la Eruditio didascalica de Hugo de San Víctor, como ha apuntado recientemente Julian Weiss, The Poet's Art. Literary Theory in Castile c. 1400-60, Oxford, 1990, págs. 73-77.

13 En el capítulo "Amor y Magia" de su Amor y Pedagogía en la Edad Media, Salamanca, 1989, págs. 85-112, y en otros puntos de este trabajo. 
la consulta de otros textos brinda ciertas claves que ayudan a entender adecuadamente el relato de las habilidades de Celestina, de acuerdo con las palabras de Pármeno ${ }^{14}$ :

Ella tenia seys officios, conviene a saber: labrandera, perfumera, maestra de fazer afeytes y de fazer virgos, alcahueta y un poquito hechizera. Era el primero oficio cobertura de los otros, so color del qual muchas moças destas sirvientes entravan en su casa a labrarse y a labrar camisas y gorgueras y otras muchas cosas

La primera de las ocupaciones de esa serie ha merecido diversos y recientes comentarios. El último de los aparecidos es obra de Ian Macpherson, quien no ha dudado en leer los dos términos, labrar y labrandera, en clave sexual ${ }^{15}$; sin embargo, tampoco se le escapa la asociación explícita que Russell transmite en su nota 146: "a labrarse: 'a coserse', alusión irónica a uno de los dos métodos empleados por Celestina para efazer virgos»". Todo indica, en cambio, que Macpherson no se ha servido de otra extraordinaria edición, la preparada por María Eugenia Lacarra, donde hallamos una noticia adicional de interés ${ }^{16}$ :

Hay aquí una alusión a la prostitución clandestina que ejercían. Las labranderas tenían mala fama y se equiparaban a las rameras, como se ve en la Carajicomedia [...], donde también el verbo 'labrar' es eufemismo de fornicar; en la poesía tradicional, 'labrarse' tenía el mismo significado.

Sin embargo, Macpherson recoge los dos testimonios que se pueden extraer de esa obra. A lo largo de la Carajicomedia, publicada en el Cancionero de obras de burlas provocantes a risa de 1519 , las putas viejas se adornan de las mismas galas que Celestina, pues son también remendadoras de virgos, maestras en preparar afeites, alcahuetas y hechiceras; además, en algún momento, hay referencia abierta al amor por el vino (así la glosa a la copla CXXI). Como sabemos, el anónimo autor de esta obra, compuesta entre 1506 y 1519 , conocía bien La Celestina y, de hecho, llegó a aludir a la vieja en la copla XX. Es la glosa a la copla XLI la que aquí nos interesa ${ }^{17}$ :

Gracia [una de las putas de su galería] es una mujer enamorada, gran labrandera; es hermosa y dispuesta, empero en sus ojos parece bien ser su

14 Citamos, como en las demás ocasiones, por medio de la edición de Peter Russell, Madrid, 1991, que nos merece el mayor de los respetos, a pesar de alguna dura e injusta reseña.

15 "Celestina labrandera", Revista de Literatura Medieval, 4, 1992, págs. 177-186.

16 La Celestina, Barcelona, 1990, pág. 128.

17 Citamos por la edición de Juan Alfredo Bellón Cazabán y Pablo Jauralde Pou, Madrid, 1974, pág. 188. 
cara la figura de la luxuria, según la copla lo declara. Es mujer que continuo está en su puerta labrando y por maravilla passa ninguno que ella no lo mire.

El ejemplo no basta por si solo para probar la pésima fama de las mujeres entregadas a esa labor; sólo parece que la costura es una excelente forma de matar el tiempo para quien ha abierto tienda y espera cliente, y que puede seguir siéndolo tras colgar la capa y dejar el oficio, como refleja otro pasaje de la Carajicomedia que tampoco se le escapa a Macpherson: "Isabel de León ha sido ramera cortesana; agora ya es jubilada y los dioses la han convertido en costurera" (ibíd., pág. 194). El ejemplo de poema popular aportado por Lacarra, que procede de la Comedia Florisea de Francisco de Avendaño: "Mis barreñas, ¡ he! / yo me las labraré", resulta un tanto light para este caso ${ }^{18}$. Ciertamente, la lírica tradicional invita a menudo a esa asociación sexual aunque desde una órbita distinta: al labrar el huerto, no al hacer labores (esto es, al coser o bordar); ése es el verbo implícito en los poemas de la serie del celebrado "No entres en huerto ajeno" (Corpus, 2039), que tiene otras tantas correspondencias en distintos universos literarios: en el Sendebar y la Historia septem sapientium como en el Milón de Mathieu de Vendôme, una comedia elegíaca en la que el labrador-marido hace saber al rey (supuesto león) que no labra su viña (en realidad, su mujer) desde que ha visto en ella las huellas de la fiera (las versiones de esta historia insertas en el Decamerón y el Conde Lucanor no sirven a este respecto) ${ }^{19}$. No obstante, la más clara resulta ser esta breve muestra extraída del cancionero tradicional (Corpus, 1821):

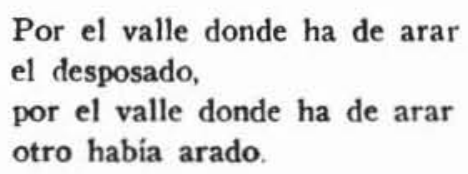

Como puede comprobarse, hasta ahora no hemos hecho sino alimentar las propuestas de la crítica previa, que Macpherson ha retomado para sostener el mensaje sexual subyacente en el diálogo entre Celestina y Lucrecia en el acto IV. Sin embargo, todo lleva a pensar que no es la relación labranderaprostituta la imperante en ese pasaje. Si las ancianas de la Carajicomedia no han dejado su antiguo oficio (espejo para todas es María de Miranda, en la copla XLVII, cuyo apetito insaciable la arrastró a ser infiel a su proxeneta

18 Lo ha tomado de Margit Frenk, Corpus de la antigua lirica popular hispánica (siglos XV a XVII), Madrid, 1987, n. 1169.

19 Aunque la comedia no se tiene en cuenta, consúltese el trabajo de T. A. Perry, "'La Huella del León' in Spain and in the Early Sindibad Tales", en Joseph R. Jones, ed., Medieval, Renaissance and Folklore Studies In Honor of John Esten Keller, Newark, 1980, págs. 39-52. 
a pesar de haber cumplido más de setenta años), no le sucede lo mismo a Celestina, a pesar de que no la han apeado de su antigua dignidad, pues como todas ellas, retiradas o no, sigue siendo la "vieja puta". No es ése, sin embargo, su modus vivendi, aunque ello no impida que Celestina sienta renacer el apetito sexual a la vista de los jóvenes o que pueda llegar a incurrir en desviaciones como el voyeurismo o la pedofilia. Más bien, las connotaciones primeras que flotan en la cabeza de un lector de hoy (y quizás en la de un contemporáneo de Rojas) nos llevan por otros derroteros: las mismas que encontramos antes en el Libro de Buen Amor, en que la buhonera se identifica con la alcahueta (hermandad que habria que extender a las hilanderas y tejedoras, en una modalidad de economía elemental en que no cabe distinguir a productores de distribuidores) ${ }^{20}$; en buena medida, coinciden también con las que se nos muestran en algunos relatos folklóricos, según pasamos a ver.

Recordemos que existe una versión medieval de la Bella Durmiente, recuperada siglos más tarde por el Pentamerone o Cunto de li Cunti de Giambattista Basile (1565-1632), en que la hermosa Talia no se hiere con un huso punzante sino con una astilla del cáñamo de la rueca de la vieja ${ }^{21}$; tampoco pasemos por alto que, en la difundidísima leyenda de Blancanieves, la bruja se acerca a la joven como vendedora de cintas, tal y como aún se percibe en la vulgata de los hermanos Grimm, sin ir más lejos. Si los nexos se buscan en ámbitos más cultos, tampoco han de faltar: en este caso, las Parcas, representadas como tres viejas tejedoras desde la Antigüedad, son la cara maldita de dicho oficio; con certeza, las brujas-hilanderas del folklore guardan algún vínculo respecto de esos personajes, aunque sea muy difícil de precisar. Por fin, no hay que pasar por alto la asociación secundaria de esa familia semántica, aún vigente en el español de nuestros días, donde la función de tercera aparece reforzada con términos como urdidora, sinónimo de "maquinadora" o "embaucadora", y donde tejemaneje nos sirve para hablar de un asunto o negocio más bien turbio (algo de esto se indica ya en Macpherson, op. cit., pág. 181, n. 6).

De vuelta al Libro de las confesiones, nos encontramos con referencias de distinto valor. El capitulo CXLII, citado más arriba, aporta muy poco, pues fundamenta su crítica contra los labradores de seda o de lana sobre los aspectos más comunes; son los mismos que llamarán la atención de Fray Hernando de Talavera a finales del siglo xv o Antonio de Torquemada a mediados de la siguiente centuria: "non deuen fazer labores vanas, asy commo

\footnotetext{
20 Con todo, nuestro querido Libro de las confesiones recoge y critica a intermediarios y otros especuladores.

at Véase Johannes Bolte y Georg Polivka, Anmerkungen su den Kindern und Hausmärchen der Brüder Grimm, Hildesheim, 1963.
} 
çintas muy loçanas e bolsas, luas, cabeçadas pintadas e garridas e colares e brocales e otras cosas vanas" (fol. 243r) ${ }^{22}$. Ahora bien, en el Códice XXI de la Colegiata de León, el capítulo CLVI (ilegible en el manuscrito madrileño), "De los menesteres que son para cobertura et guarda de los cuerpos", se descubre la pésima reputación de los talleres de costura (en ese punto, cabe pensar que las sospechas de Lacarra y Macpherson tienen un fundamento de notable solidez), donde las jóvenes recibían lecciones adecuadas para perder su honra (fol. 196r):

Estos mesmos pecados demandarás a las filanderas, que ayuntan en una e están fasta la media noche diziendo muchos males, e dizen ally muchas caçorrías e luxurias, e aprenden las moças lo que nunca sopieron; e de aquellos pecados, sábenlos e después óbranlos. Estas tales son las escuelas de los diablos, do se aprenden e do se enseñan las sçiençias del infierno.

A la luz de los testimonios aducidos, cuando teje, Celestina deja trazas de sus demás oficios; al mismo tiempo, su taller de corte y confección se revela como una simple tapadera para cualquier tipo de negocio ligado al mundo del sexo; en último término, su condición de buhonera le permite echarse a la calle para buscar sangre fresca. Así pues, las piezas del conjunto encajan a las mil maravillas.

Por lo demás, tal y como se dijo en su lugar, el resto de los elementos de ese retrato no presenta mayores dificultades. La descripción de Pármeno tiene su complemento en la de Lucrecia, cuyo discurso coincide punto por punto con la del criado; sin embargo, en un momento, la sirvienta carga las tintas sobre la competencia de Celestina en cosmética y Medicina, algo que no podía extrañar al público de la Trotula major o De passionibus mulierum, de la Practica domine Trotta ad provocanda menstrua (i título revelador para quien repasa los simples de la oficina celestinesca!) o de esos dos tratados de cosmética titulados $U t$ de curis y De ornatu mulierum o Trotula minor, que se atribuyen, como los demás, a la celebrada Trota o Trótula ${ }^{23}$. Para el hombre del Bajo Medievo, Trota era la figura principal en medicina de

23 En el Tratado de cómo vestir del primero y en distintos momentos del "Coloquio de los vestidos" del segundo; para éste, véase el trabajo de Lina Rodríguez Cacho, Pecados sociales y literatura satírica en el siglo XVI: los 'Coloquios' de Torquemada, Madrid, 1989, págs. 103-165.

23 Aunque lejanamente, ¿tendrá algo que ver ese nombre con el de Trotaconventos? Claro está que el antropónimo de la vieja del Libro de Bucn Amor no ofrece mayores dudas en su relación con "trotar", verbo de origen alemán de acuerdo con los diccionarios etimológicos de distintas lenguas románicas, que pasó al espafiol a través del francés o del italiano. ¿Qué hacer, entonces, con el problemático trottonarius documentado en el latín de Vegecio en fecha muy anterior? El Glossarium Mediae et Infimae Latinitatis de Du Cange ofrece interesantísimos testimonios tanto en latín como en francés (así trotari por adulteri o el revelador nombre Trote-d-pie, paralelo al de Juan Ruiz). 
mujeres (Obstetricia y Ginecologia) que habian visto los siglos; para cualquiera medianamente informado, su nombre se asociaba de forma inmediata con la ilustre Escuela de Salerno. No obstante, hoy tenemos razones de sobra para pensar que, en realidad, sus tratados fueron compuestos por diversos autores en torno al siglo XII ${ }^{24}$; por otra parte, su fama llevó a que muchos de los escritos de materia ginecológica del Medievo le fuesen atribuidos. Una y otra vez, la reatidad social y la cultura libraria coinciden y se plasman en Celestina.

Sólo al cierre, se comprueba que ni el Macer floridus ni el Hortus sanitatis han logrado expulsar aún a Marbodio del laboratorio de la vieja: "Señora, perfuma tocas, haze solimán, y otros treynta oficios. Conoce mucho en yiervas, cura niños, y aun algunos la llaman vieja lapidaria." La última referencia es harto sintomática, pues, hacia finales del siglo $\mathrm{xv}$, los tratados de Medicina al uso habían limitado o excluido la presencia de las piedras: mientras distintos minerales formaban todavía parte de múltiples recetas, se prescindia de cualquier referencia a sus virtudes simpáticas, en boga un par de siglos atrás ${ }^{25}$. Hemos de aceptar que, en este aspecto, las habilidades de Celestina se apartan sobremanera de la que se puede llamar medicina oficial con la intención de reforzar su faceta de hechicera. La paradoja reside en que los principales tratados médicos de época no dudan en recurrir a viejas como Celestina aunque con intención opuesta: para desligar o curar el mal de amores, a la manera del Lilio de Medicina del admirado maestro de Montpellier Bernardo de Gordonio (compuesto ca. 1300 e impreso en versión castellana en 1495) y en el Sumario de la medicina de un contemporáneo de

24 Hay numerosos ejemplares manuscritos y ediciones del De passionibus mulierum, que fue traducido al italiano, francés, inglés, alemán y catalán (ms. 3356 de la Biblioteca Nacional de Madrid). Véase Guy Beaujouan, "Manuscrits médicaux du Moyen Age conservés en Espagne", Mélanges de la Casa de Velásques, 8, 1972, pág. 199. Un códice latino de la mayor importancia es el ms. 119 de la Biblioteca de la Universidad Complutense de Madrid. Para una sucinta pero rica información sobre Trótula, véase la entrada correspondiente del Dictionnaire des Lettres Françaises. Le Moyen Age (París, 1992), págs. 1455-1456; más detalles en John F. Benton, "Trotula, Women's Problems, and the Professionalization of Medicine in the Middle Ages", Bulletin of the History of Medicine, 59, 1985, págs. 30-53.

25 Dosis de una y otra hay en la obra alfonsi, como se pone de manifiesto en Marcelino V. Amasuno Sárraga, La materia médica de Dioscórides en el Lapidario de Alfonso $X$ el sabio. Literatura y ciencia en la Castilla del siglo XIII, Madrid, 1987. Claro está que aún había lectores para los viejos libros de piedras, como se comprueba en el ms. 1341 de la Biblioteca de Palacio de Madrid, en sus fols. 16v-20r (un Alberto Magno, por cierto). Las virtudes de las piedras para quien las porta aún se dejarán sentir en aquellas secciones dedicadas a los venenos en varios tratados médicos: el libro VI del Dioscórides de Andrés Laguna, sin ir más lejos, es un buen ejemplo de ello; como creencia supersticiosa, el contacto con las piedras seguirá hasta el presente. 
Rojas, Francisco López de Villalobos (1498) ${ }^{20}$. Esa empresa resulta plausible desde la moral cristiana más observante; de hecho, es el curioso envés de la común profesión de las vetulae, entregadas a la caza de la puella en la literatura como en la vida ${ }^{2}$.

Centrémonos aún más, aunque sólo sea por un instante, en este último y polémico aspecto de la obra, que da el título a nuestro trabajo; volvamos de nuevo sobre la relación que guardan la brujería, la magia o la hechicería con las demás industrias celestinescas. Ana Vian acaba de volver sobre este fundamental aspecto, con su precisión e inteligencia características, para ofrecer un status quaestionis y, en último término, determinar cuál es la función de esos ingredientes en $\mathrm{La}$ Celestina ${ }^{28}$; en un momento, Vian vacia trabajos anteriores en que se pasa revista a las sustancias de la cueva de la vieja: los preparados por J. M. Fuentes de Aynat, Félix Marti-Ibáñez y Modesto Laza Palacios ${ }^{29}$. La intención de Vian en ese punto no es otra que deslindar los fármacos de uso común en Medicina de aquellos otros que persiguen fines eróticos, y éstos, en última instancia, de los compuestos y simples que, por fuerza, hemos de remitir al universo de las ciencias prohibidas.

En el laboratorio celestinesco hay sustancias de origen vegetal, animal y mineral usadas en la preparación de perfumes, drogas y estimulantes, si bien no faltan remedios para los males más comunes. Junto a los afrodisíacos, como el alfócigo, hay otras sustancias menos sospechosas en un principio; abundan en especial las plantas empleadas en medicina femenina: la galega es galactógena y facilita el parto, como la consuelda; el marrubio, igual que el ajenjo, provoca el menstruo y propicia la expulsión de la placenta (aunque también se emplee para curar los comunes constipados); por otra parte, la milenrama (achillea millefolium) es buen hemostático y sirve para contrarrestar las disfunciones que aparecen con la menopausia. La Ginecología,

\footnotetext{
26 Ambos textos han sido recogidos previamente por Cátelra, op. cit., págs. 213-216 y 87 , respectivamente.

27 Los documentos en que se previene a la sociedad acerca de sus maldades han sido recogidos por Cátedra (op. cit., págs. 110-111), quien parte de Vincent de Beauavis para llegar a la época de Rojas; en todos esos testimonios, la vetula es instrumentum Diaboli.

${ }_{28}$ "El pensamiento mágico en Celestina, 'instrumento de lid o contienda'", Celestinesca, 14, 1990, págs. 41-91.

20 Respectivamente, "La botica de Celestina", Medicamental: Edición para el farmacéutico, V, 44 [1951], págs. 267-268; "The Medico-Pharmaceutical Art of La Celestina: a study of a fifteenth-century spanish sorceress and 'dealer in love'", en International Record of Medicine and General Practice Clinics, 169 [1956], págs. 233-249, y El laboratorio de Celestina, Málaga, 1958. En el futuro, con más calma, daremos a la luz unas cuantas apostillas de interés sobre los simples de origen vegetal; por lo que respecta a los simples recogidos por Joaquina Albarracin Navarro y Juan Martínez Ruiz, "Farmacopea en La Cclestina y en un manuscrito árabe de Ocaña", en Criado de Val, La Celestina y su contorno social, op. cit., págs. 409-425, es preciso recordar que hay coincidencias parecidas en otros textos médicos y recetarios de esa misma época.
} 
no obstante, nos revela también su lado oscuro, pues, como recuerdan Vian y otros estudiosos, no es de ningún modo fortuito que brujas, parteras y curanderas aparezcan asociadas en varios procesos inquisitoriales y que, en ocasiones, acaben en el fuego. Sin necesidad de llegar tan lejos, a nadie se le puede esconder la cara obscura de la profesión de Celestina, ligada a la sexualidad en todas y cada una de sus facetas.

Aún en nuestros dias, el especialista en tales materias despierta suspicacias, reparos e incluso rechazos enconados por razones de orden moral al abordar problemas como las disfunciones sexuales, la contracepción o el aborto (un capítulo científico no menos problemático hoy es el de la moderna ingenieria genética). Tales menesteres, ausentes de los manuales de época, eran una realidad cotidiana que quedaba en manos de personajes marginales como Celestina. En particular, en aquella "especialidad médica" que atiende al mal de amores en sus formas diversas, se revela una mayor distancia respecto de la medicina oficial, según se comprueba hoy mismo en culturas primitivas y no tanto, como la musulmana y la oriental, donde se pagan fortunas por supuestos afrodisíacos como el cuerno de rinoceronte. En este terreno, la historia nos enseña que, en el negocio del sexo, característico de todo inframundo, es muy difícil establecer los límites entre brujas, hechiceras, alcahuetas, prostitutas, comadronas (ya sea para asistir a la parturienta o con la intención de provocar un aborto), remendadoras de virgos y otras viles ocupaciones con ellas asociadas. El hecho de que Celestina se muestre como una especialista en diversas disciplinas médicas no podía extrañarle a una sociedad que habia hecho un mito del nombre de Trota, como ya hemos señalado; ahora bien, la presencia de la mujer entre los galenos medievales levantaba no pocas sospechas, según leemos en la Chirurgia (1312) de Henri de Mondeville, que carga las tintas contra todos cuantos han invadido el espacio reservado al médico: truhanes de toda condición, prostitutas, alcahuetas, comadronas y brujas ${ }^{30}$.

Sabemos que Celestina era maestra en dichas labores sin necesidad de rastrear pruebas inculpatorias en su oficina; ahora bien, si perseguimos las propiedades prohibidas de sus simples (o especias, pues, durante el Medievo, especiero es el nombre común del farmacéutico), podemos sacar a relucir la función que ciertas plantas celestinescas tienen en la medicina popular: en ella, el romero es un excelente estomacal y antiespasmódico, pero, como el perejil, la mostaza (sobre todo, la negra, brassica nigra, tal vez la misma a la que se refiere Pármeno) y la ruda (hasta tal punto familiar para los personajes de la obra y para su público que se apela al refrán: "Es más conocida que la ruda"), es un poderoso abortivo del que todavía se tiene noticia

30 Véase Heinrich Schipperges, El jardin de la salud, Barcelona, 1987, pág. 115. 
en ámbitos rurales; también los emenagogos hacen las veces de abortivos, como el ajenjo y el marrubio, ya citados, o el culantrillo de pozo (más celebrado como tónico capilar) ${ }^{31}$. Sin embargo, errarán cuantos piensen que el conjunto de los productos del laboratorio de Celestina tiene sólo indicaciones sexuales y prohibidas; valga como muestra, el estragón o dragoncillo (artemisia dranunculus), que, en medicina alopática o casera, sirve para despertar el apetito (a estas alturas quizá sea necesario apostillar que no aludimos a la libido sino a las ganas de comer).

Avancemos un nuevo paso para recordar que el mundo de las brujas y el del sexo están ligados de forma estrecha no sólo en las aproximaciones eruditas contemporáneas sino también en los propios manuales médicos del pasado ${ }^{32}$. Para dar sustento a esta afirmación, no tenemos más que acudir al Dioscórides de Andrés Laguna y leer una sabrosa anécdota relativa al beleño (hyoscyamus niger, origen del bellísimo verbo embeleñar) o su no menos sutil comentario respecto del solano (nigra o dulcamara en especial). Según el doctor Laguna, el solano es un poderoso alucinógeno sexual, como le enseñó la experiencia durante su estancia en Lorena; merece la pena traer a colación sus palabras ${ }^{33}$ :

[...] fue una olla medio llena de vn cierto ungüento verde, como el del populeón [calmante hecho con manteca, adormidera, belladona y otros ingredientes], con el qual se vntauan, cuyo olor era tan graue y pesado que mostraua ser compuesto de yeruas en vitimo grado frías y soporiferas quales son la cicuta, el solano, el veleño y la mandrágora, del qual vngüento por medio del alguazil que me era amigo procuré de hauer vn buen bote con que después en la ciudad de Mets hize vntar de pies a cabeça la muger del Verdugo, que de celos de su marido hauia totalmente perdido el sueño y buéltose quasi medio phrenética, y esto ansí por ser el tal subjecto muy apto, en quien se podían hazer semejantes prueuas, como por hauer prouado infinitos otros remedios en balde, y parecerme que aquel era mucho a propósito y no podia dexar de la aprouechar según de su olor y color fácilmente se colegia; la qual súbito

31 Aparte, habia otros modos de pecar con las plantas, según se nos revela en Pilar García de Diego, "Religión o superstición: Supersticiones prohibidas por los Concilios", en Homenaje a Julio Caro Baroja, Madrid, CSIC, 1978, págs. 425-429. Tampoco faltaron disposiciones como la del Concilio de Braga del año 572, cuyo canon lxxii tiene un título harto significativo: De eo quod non liceat herbas medicinales cum aliqua observatione colligere. No olvidemos el primero de los testimonios extraído del Libro de las confesiones.

${ }_{32}$ Nos parece harto significativo que el conocido libro de Claude Kappler, Monstruos, demonios y maravillas a fines de la Edad Media, Madrid, 1980, dedique una sección completa a "La bruja, monstruo sexual"; sobre esta misma materia versa la labor de R. E. L. Masters, Eros and Evil: The Sexwal Psychopathology of Witchcraft, Nueva York, 1962.

$3 s$ La cita procede del facsímil del ejemplar filipino, que hemos recuperado gracias a la labor de un ilustre equipo que ha coordinado Alfredo Alvar Ezquerra (Madrid, 1991). 
en siendo vntada con los ojos abiertos como conejo, pareciendo también ella propriamente vna liebre cozida, se adurmió de un tan profundo sueño que jamás pensé despertarla; por donde con fuertes ligaduras y frictiones de las extremidades, con perfusiones de azeyte costino y d'euphorbio, con sahumerios y humo a narizes, y finalmente con ventosas, la di tal priessa que al cabo de xxvj horas la restituy en su juyzio y acuerdo, aunque la primera palabra que habló fue: ‘ Por qué en mal punto me despertastes, que estaua rodeada de todos los plazeres y deleytes del mundo?' $\mathrm{Y}$ bueltos a su marido los ojos, díxole sonriéndose: 'Tacaño, hágote saber que te he puesto el cuerno y con vn galán más moço y más estirado que tú'; y diziendo otras cosas muchas y muy estrañas se deshazía porque d'allí nos fuéssemos y la dexássemos boluer a su dulce sueño, del qual poco a poco la diuertimos aunque siempre la quedaron ciertas opiniones vanas en la cabeça; de donde podemos conjecturar que todo quanto dizen y hazen las desuenturadas bruxas es sueño causado de beurages y vnctiones muy frias, las quales de tal suerte las corrompen la memoria y la phantasía que se imaginan las cuytadillas y aun firmissimamente creen hauer hecho despiertas todo quanto soñaron durmiendo.

La cita resulta de lo más atinado por cuanto nos recuerda que los emplastos y brebajes de brujas procuraban el goce sexual, fuese el suyo propio o el de sus clientes, a través del contacto físico o con ayuda de alucinógenos. De ese modo, el universo celestinesco no sólo se trasluce en los textos literarios y los documentos de época sino también en los tratados científicos, aun cuando el enfoque de unos y otros testimonios sea muy distinto.

Aunque la solución del dilema no resulte fundamental, hemos de admitir que nunca se sabrá a ciencia cierta cuál fue la verdadera opinión de Fernando de Rojas acerca del poder de las brujas, magas o hechiceras, pues nada invita a adivinar al autor a través del universo de sus propios personajes. Cualquiera que fuese el parecer del Bachiller al respecto ${ }^{34}$, nuestra postura ha de oscilar entre los paradigmas brindados por dos maestros: Peter Russell, quien ve en la magia un ingrediente fundamental para el desarrollo de la obra ${ }^{35}$, y María Rosa Lida, para quien la magia "no es un elemento orgánico del drama ni está integrado en la representación del personaje como lo están, por ejemplo, su codicia, su sentido de honra, su religión" (La originalidad, pág. 541). Tras revisar las señas de identidad de Celestina, hora es de que aticemos el fuego en torno a esta apasionante polémica a través del estudio de las piezas con que se justifica la visita de la vieja a Melibea: la entrega del hilado, la petición de su cordón y el dolor de muelas de Calisto,

34 No nos cuesta ningún trabajo admitir la opinión que mantiene Cátedra en lo que atañe a Rojas: "Así pues, difícil será encontrar contemporáneos o antecesores intelectuales directos del Tostado - como también ha expuesto Russell con las miras puestas en Celestina - que pusieran en duda el posible papel de la magia en la práctica de maleficios con fines amorosos" (op. cit., pág. 89).

as "La magia como tema integral de La Celestina", en sus Temas de "La Celestina" y otros estudios del "Cid" al "Quijote", Barcelona, 1978, págs. 241-276. 
mal menor cuyo remedio quedaba en manos de barberos y ministrantes. En esos elementos, radicaba un mensaje que el público de la obra hubo de percibir con tanta facilidad como rapidez.

Por ese motivo, echamos en falta alguna nota en las valiosísimas ediciones de López Morales o Russell, aunque no se haya olvidado en Lacarra ${ }^{36}$. Todo lo dicho hasta ahora acerca del dolor de muelas de Calisto tiene su origen en un par de trabajos: el primero es de M. Dominica Legge ${ }^{37}$; el segundo, en deuda con el anterior, es de Geoffrey West ${ }^{38}$. Ahora bien, West no es capaz de aportar un solo ejemplo peninsular en línea con los reunidos por Legge, procedentes de las poesías occitana (la de Peire Vidal) y francesa (Guillaume de Lorris o el Lai de l'Ombre); así, afirma: "In Spanish literature, I have not been able to find any parallel examples" (ibid., pág. 4). Los testimonios ultrapirenaicos reunidos por Legge parecen dar una respuesta al enigma de $\mathrm{La}$ Celestina que West no dudó en aceptar: cabe hermanar el dolor de muelas con el que se deriva del amor por la intensidad con que ambos se dejan sentir. Sin embargo, la solución no cae de ese lado, según se ve por un precioso testimonio, un extraordinario ejemplo de refrán vivo aún: "Mal de muelas, mal de amores". Es una lástima que esta reveladora paremia no aparezca (quizás no hemos tenido la suerte de encontrarla o no la hemos sabido perseguir) en ninguna de las colecciones de refranes que hemos consultado desde Correas hasta nuestros dias; la seguridad, a este respecto, no procede sino de nuestra propia competencia idiomática ${ }^{39}$.

Las muelas del juicio o cordales aparecen, por regla general con fuerte dolor, en la adolescencia, la misma época en que la pasión erótica se enseñorea de nuestros cuerpos; asi lo indican Aristóteles, en De animalibus (501b), y Plinio, en su Historia natural (XI, 63), quienes sostienen que éstas salen en torno a los veinte años; por su parte, San Alberto Magno, en

* A ese respecto, señala: "desde muy temprano en la Edad Media se comparaba el dolor de muelas con el exceso de pasión amorosa", pág. 176 de su edición. También recoge el poema "Niña y viña" en torno al cordón como elemento caracterizador de una sexualidad abierta, que veremos enseguida.

37 "Toothache and Courtly Love", French Studies, 4, 1950, págs. 50-54, y

38 "The Unseemliness of Calisto's Toothache", Celestinesca, 3, 1979, págs. 3-10.

30 Para la esencia del refrán y su inserción en el discurso, remitimos a Fernando Lázaro Carreter, "La lengua de los refranes: ¿espontaneidad o artificio?", en sus Estudios de lingüística, Barcelona, 1980, págs. 219-232. Por cierto, el ejemplo italiano aducido por Joaquín Casalduero para explicar el pasaje de La Celestina, en "La señora de Cremes y el dolor de muelas de Calisto", en Criado de Val, La Celestina y su contorno social, op. cit., págs. 75-79, no vale tampoco para nuestro caso; en la paráfrasis de Salvatore Bataglia, se resume: "Dolere a qualcuno qualche dente: provare vivo interese, amore, disiderio (por lo piu non corrisposto)." El profesor Casalduero recordaba haber oído este refrán en Castilla, aunque no logró documentarlo en ninguna de las colecciones conocidas; si el refrán que tenía en mente es el que sospechamos, en realidad cuenta con abundantes documentaciones próximas al patrón: “Al que le duele una muela, que se la saque." 
su De animalibus libri $X X V I$, apunta que siempre nacen "cum dolore et calore febrili" (II, 54). Por ahí, probablemente, pudo venir esa asociación, que, por lo que sabemos, no guarda ningún parentesco con la materia médica del período. No obstante, dicho refrán se aplica ahora ante cualquier dentalgia y a cualquier edad; eso sí, cuando se le recuerda a alguien que peina canas ha de hacerse en tono jocoso o con un punto de ironia. A ese respecto, Aristóteles y Plinio aseguran que su aparición a veces se retrasa hasta los ochenta años y que cuanto más tarde se muestran más intenso es el dolor que se deriva. Claro está que la asimilación con el mal de amores es sencilla en ese punto, pues la llaga amorosa se encona mucho más con los años y, en edad provecta, puede derivar en el indecoroso y funesto turpe senis amor. En este punto, viene en nuestro auxilio un último, célebre y significativo refrán: iA la vejez, viruelas!

Según el Breve Diccionario Etimológico de la Lengua Castellana de Corominas, el término cordal, con significado de "muela del juicio", se documenta por vez primera en la obra de Fernando de Herrera (1580). Esta referencia supone un avance respecto de la que ese erudito brinda en su Diccionario Crítico-Etimológico de la Lengua Castellana, que nos fuerza a refrescar la memoria respecto de un célebre pasaje de la primera parte del Quijote (1605); es el mismo texto que se recoge en el Diccionario Critico Etimológico Castellano c Hispánico de Corominas-Pascual. Sin embargo, hemos podido comprobar que cordal se incluye ya en el Vocabulario españollatino de Nebrija, ca. 1493-1495, donde se registra como una voz común ${ }^{40}$. Es fácil establecer una asociación adicional entre el mal de muelas (las cordales, de la cordura o del juicio, se entiende, y en ningún momento ha de escapársenos la celebérrima presentación de la enfermedad amorosa como propia "del meollo" o del corazón, en última instancia) ${ }^{41}$ y la pasión erótica, puesta de relieve por medio del cordón, un elemento que apenas si logra encubrir una sexualidad abierta desde el mundo clásico (recordemos que un ceñidor o faja es el símbolo de la belleza toda tanto de Hera, Iliada, 14, 153 y sigs., como de Venus, cuyo cinturón tiene además propiedades mágicas); esa asociación seguía viva en la Edad Media, tal como se refleja en el poemario tradicional. Junto a la celebrada glosa de "Niña y viña, peral y habar /

40 Por desgracia, no hemos podido consultar el dato en el valioso Diccionario (en prensa) que, sobre los textos médicos medievales, ha preparado un equipo coordinado por María Teresa Herrera, en que participan profesores de las Universidades de Salamanca, Madrid y Wisconsin-Madison. Como adjetivo relativo al corazón, aparece, por ejemplo, en el Tratado de las apostemas de Diego el Covo (ed. de María Teresa Herrera, Salamanca, 1983, pág. 158, v. 29).

11 No olvidemos que la pena tiene un sinónimo medieval en la voz cordojo (lat. cor-dolium). 
malo es de guardar" (n. 314C), cordón y cinta incluidas, Margit Frenk ha logrado reunir en su Corpus otras composiciones de evidente interés:

¡Cordón, el mi cordón,

ceñidero de mi lindo amor! (n. 415)

Isabel, Isabel,

perdiste la tu faja:

¡Hela por do va.

nadando por el agua! (n. 1694)

Y la mi cinta dorada

¿. por qué me la tomó

quien no me la dio?

$$
\text { [...] (n. 237) }
$$

Por mi mal me lo tomastes,

cavallero, el mi cordón. (n. 359)

El cordón, en otros casos, es el de los cabellos, con un erotismo sólo algo más suave (n. 480 , como también puede serlo la citada n. 237, con una dimensión erótica que tampoco se nos escapa en los nn. 353 y 379), o no se precisa de dónde procede (las cintas de nn. 24 y 635, el cordoncillo de n. 676 o la faja de n. 1694). No es en absoluto casual que la Urraca del Arcipreste le entregue una sortija a la jovencita que va a embeleñar (pues esta alcahueta aparece revestida de poderes semejantes a los de Celestina) y que, a cambio, le solicite una sola y valiosa prenda: su cinta (son las estrofas 916 y 918) ${ }^{42}$.

Ya en la literatura griega es patente el significado erótico de la voz zóne, "ceñidor", documentado con profusión desde Homero (así, la expresión "desatar el cinturón" [zónen lysaszai] vale lo mismo que "unirse al prometido"). Dejamos el rastreo justamente en este punto por cuanto sabemos que Nicasio Salvador Miguel ha comenzado a recoger de forma sistemática aquellos textos en los que el cordón tiene una dimensión erótica indudable. Por cierto, aunque a lo lejos, al final del siglo xv quedaba clara constancia del hermanamiento erudito de esas dos palabras, especialmente en clave musical, en obras tan afamadas como el Variarum de Casiodoro ("hinc etiam appellatam aestimamus cordam, quod facile corda moueat", 2, 40, 12) o las Etymologiae de San Isidoro ("chordas autem dictas a corde quia sicut est pulsus cordis in pectore, ita pulsus chordae in cithara", $3,22,6$ ), que no se le es-

\footnotetext{
42 Esta es la primera de las dos victorias irrefutables del Arcipreste, ya que la de don Melón no vale adjudicársela, aunque hayamos dicho en otro lugar que su única conquista indudable, a pesar de que la muerte la frustre, es la de doña Garoza (Carlos Alvar y Ángel Gómez Moreno, Historia crítica de la literatura hispánica, 2: La poesía épica y de clerecía medievales, Madrid, 1988, pág. 121). Con Jacques Josef y Alberto Blecua, pensamos hoy que, cuando se dice que "fizo venir Urraca la duefía al rincón", se nos comunica que el Arcipreste poseyó a la joven a su antojo.
} 
capan a A. Ernout ${ }^{43}$. En nuestra lengua vernácula, no sólo cabia la confusión respecto del étimo: cordal, amén de su alternancia como adjetivo con "cordial" y de su significado de "nuela del juicio o de la cordura", también designaba una sencilla cuerda al menos desde el siglo xin ${ }^{44}$.

Hora es de que sumemos estos testimonios, eruditos o populares. De ese modo, habremos de concluir que la asociación establecida no es en absoluto rebuscada ni depende de forzados rastreos. El contenido erótico de la embajada de Celestina cerca de Melibea era de una claridad meridiana para un contemporáneo de Rojas cualquiera que fuese su formación. Por eso, Calisto alaba el ingenio de Celestina cuando le relata cómo ha justificado su visita a la recelosa joven, porque el galán ha captado inmediatamente la segunda y diáfana intención que se deriva de la respuesta de la alcahueta (acto VI):

Cel. ¿ ¿Qué, señor? Dixe que tu pena era mal de muelas $[\ldots]$

Cal $-\mathrm{i} \mathrm{O}$, maravillosa astucia! $[\ldots]$

Si nos dejamos llevar por ese común exceso crítico que da vida a los personajes literarios más allá de sus palabras, hay que preguntarse si Melibea ha entendido también el propósito de la mensajería, aunque sea joven aislada de malas influencias y protegida; en cualquier caso, conocedora como se muestra de la poesía popular, no se le pasaría por alto la función que en ella tienen cordones y cintas ${ }^{45}$. Nada impide creer que lo haya captado a la primera, pues su enfado y su rechazo iniciales admiten una doble lectura: en amor cortés, en artes amatorias y en obras de esa misma época (la Historia de duobus amantibus, por ejemplo) es norma el rechazo inicial y el asedio prolongado. Melibea, por su tono, en un punto teme haber espantado a Calisto, pues el joven es algo así como su última oportunidad: ella no tiene entre trece y quince años, edad ideal para una amada según un sabroso poema de Carvajal, sino veinte, como revela Peblerio en su llanto ${ }^{46}$. En todo

4s "Cor et c(h)orda", en Philologica, Paris, 1957, vol. II, págs. 179-184 [182]. Muchos más materiales sobre cor y otras formas afines se reúnen en la tesis de licenciatura de Teresa Jiménez Calvente. "Estudio estructural del campo semántico de los verbos de recuerdo en latín" (UAM, 15 de julio de 1991).

4 Martín Alonso, en su Diccionario medieval español, aduce un primer testimonio del Libro de Alexandre. 1509b, y otro más de la Gaya ciencia de Pero Guillén de Segovia.

45 También habría mucho que decir sobre las virtudes del cordón de Melibea, que tantas reliquias habia tocado. En este plano, la burla no hubo de esperar a las corrientes erasmianas, como sabemos muy bien, sino que dejó testimonios desde el siglo XII. Sobre las virtudes de ciertos cordones, más bien sogas, recordamos el chiste de Quevedo en el Buscón; aunque no llegue a tal punto, la alusión de Celestina ha de considerarse en clave jocosa o irónica.

46 Unos cuantos tenemos siempre presente este sabroso dato aportado por Domingo Ynduráin en "Un aspecto de 'La Celestina'", en Estudios sobre el Siglo de Oro. Homenaje a Francisco Ynduráin, Madrid, 1984, págs. 521-540. 
caso, cualquier lector, por muy ingenuo que fuese, hubo de seguir el juego de Celestina en ese punto; por eso, en el amor de Melibea por Calisto, con supuesto origen en las artes diabólicas, tuvo que ver una nueva ironía del autor, quien, en una clave que costaba poco interpretar, exponia la caida de una joven guardada hasta ese momento con gran recato.

Por cierto, no es menos irónico que Celestina, que se tiene por hábil oficial en materia médica, tenga que recurrir a la intercesión de los santos para curar una de las dolencias más comunes y con mayor número de remedios ${ }^{47}$. En la vida real, con toda seguridad, jamás habria bastado esa vana excusa, a no ser que la parte interesada viese con buenos ojos la embajada de la vieja. En todo caso, la entrada de Celestina en casa de Melibea añade un nuevo matiz irónico, pues el médico, en el juramento de Hipócrates como en la Regula Benedicti, debia ser una persona de moralidad ejemplar ${ }^{48}$; Celestina, por medio de sus visitas, tan semejantes a las de un médico a sus pacientes ${ }^{49}$, no cura ni las almas ni los cuerpos sino todo lo contrario: pierde las primeras y destruye los segundos.

Sea como fuere, los continuadores de la obra vieron que el inframundo de La Celestina, magia incluida, proporcionaba una materia literaria del mayor interés. Desde luego, Fernando de Rojas pudo desarrollar la trágica historia de Calisto y Melibea sin recurrir a la alcahueta-hechicera y a sus malas artes; como quiere Alan Deyermond, es cierto que el amor de la pareja puede explicarse "in merely human terms of psychological cause and effect" 50 ; sin embargo, Celestina, sus argucias y su universo todo consiguen que el

47 Cuatro recetas distintas ofrece en su breve extensión el Compendio de Medicina del Doctor Gómez de Salamanca, ed. de Marcelino Amasuno, Salamanca, 1971.

48 De ahí la comparación de Cristo con un médico de almas o físico desde San Jerónimo, como vemos en la Disputa entre un moro filósofo y Gonzalo Morante sobre la Trinidad y la Encarnación, que se recoge en Isaac Vázquez Janeiro, ed., Tratados castellanos sobre la predestinación y sobre la Trinidad y la Encarnación del Maestro Fray Diego de Valencia OFM (siglo XV), Madrid, 1984, pág. 171. Además de ser altamente hipotética la autoría y endebles las pruebas para demostrarla, no vale la enmienda de "Hijo suyo" por físico.

49 Y no es la primera vez que se nos muestra esa relación, pues un grabado de su predecesora, la Cárcel de Amor, inserta una imagen de Leriano enfermo idéntica a las que se muestran en diversos tratados médicos, como el Fasciculum Medicinae de Johannes de Ketham.

${ }_{50}$ Es una atinadisima frase de su "Hilado - Cordón - Cadena: symbolic equivalence in La Celestina". Celestinesca, 1, 1977, págs. 6-12. Tan certero como siempre, Cátedra afirma: “[...] la propia utilización de la magia es una opción que no carece de importancia, puesto que es evidente que el género no la exigía, ni a Rojas ni a nadie: de haber querido plantear en términos meramente idílicos el comercio de dos enamorados, tenía a su disposición el modelo de la Historia de duobus amantibus; y no sólo estos materiales, sino también su modelo más cercano, el Aucto $I$, además de otros textos probablemente anteriores a la obra de Rojas que se benefician de patrones comunes, como la Repetición de amores de Lucena o el recientemente exhumado Tratado de amores" (op. cit., pág. 107). 
mensaje moral sea más claro, la historia más sabrosa $y$, en definitiva, que La Celestina sea tal cual hoy la conocemos y disfrutamos. En última instancia, es lícito pensar que si nuestra tercera hubiese sido otra no habria despertado el interés que por ella se percibe en la Comedia Tidea, el Auto de Clarindo y, muy en especial, en el Auto de la hechicera de Diego Sánchez de Badajoz. Traemos estas obras al cierre por cuanto sus autores sintieron una especial atracción por el laboratorio de la vieja y sus conjuros, que recogieron como un sabroso motivo en algún momento de sus respectivas representaciones $^{51}$.

51 Como detalle curioso, recordemos que el Diablo, con su disfraz mitológico, está detrás de uno de los atentados de que fue objeto Fernando el Católico, según leemos en el Pluto furens de Pedro Mártir de Anglería, editado en 1498. Claro está que, cuando, en ése y otros casos, se dice que Satanás ha instigado una acción malévola, se trata, más que nada, de una manera de hablar. 